\title{
Book Review: Forensic Science and Humanitarian Action: Interacting with the Dead and the Living
}

By Roberto C. Parra, Sara C. Zapico, and Douglas H. Ubelaker, John Wiley \& Sons. 2020. ISBN: 978-1-119-48196-6 \$225.00 (Print)

Reviewed by Amanda N. Friend, SNA International in support of DPAA, Hawaii

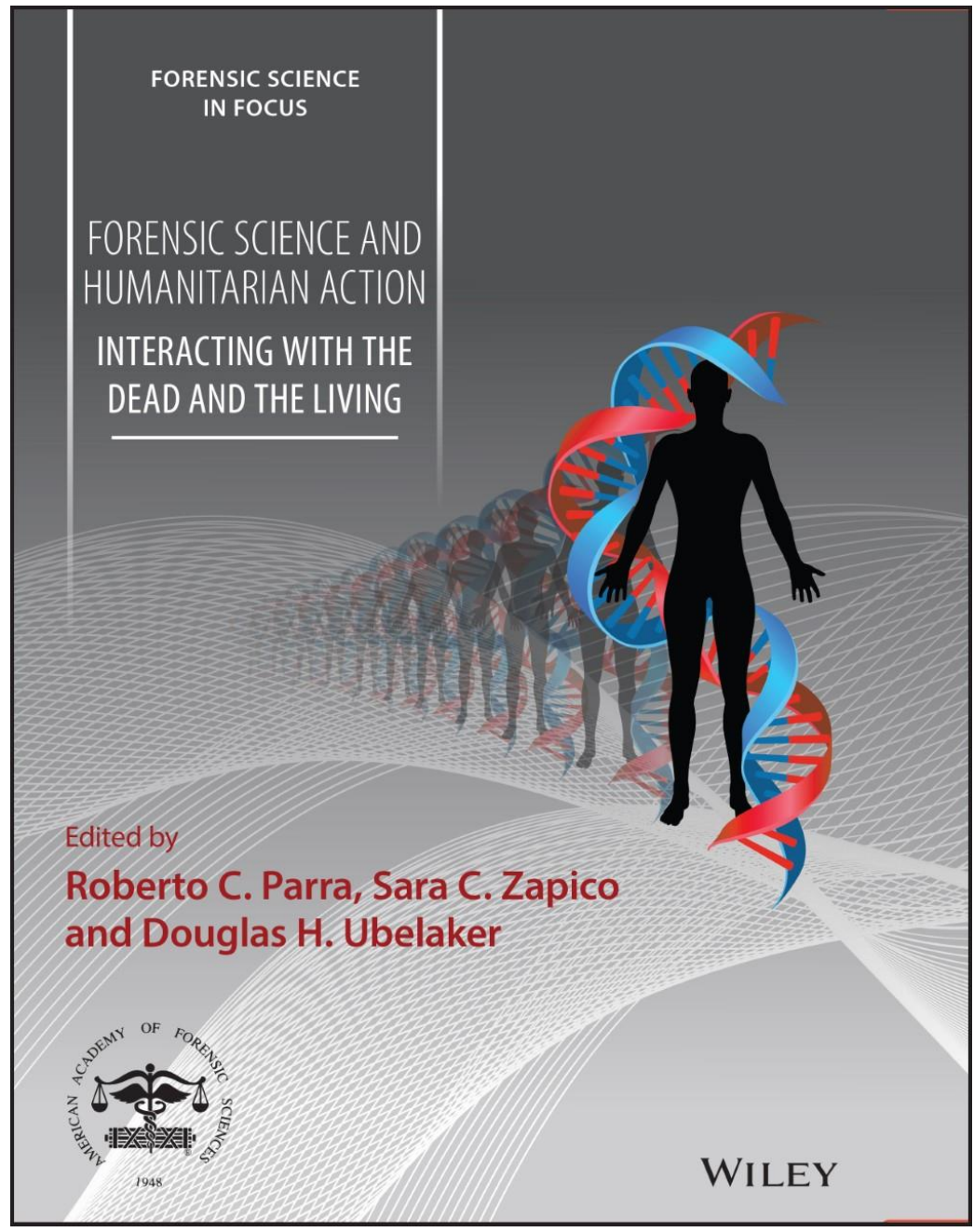

Forensic Science and Humanitarian Action: Interacting with the Dead and the Living (2020) edited by Roberto C. Parra, Sara C. Zapico, and Douglas $\mathrm{H}$. Ubelaker is an interdisciplinary two volume work focusing on "all aspects related to forensic identification of human remains, their posthumous dignity, agency, the legal foundation that protects them, and the impact on the living". The two volumes include 47 chapters and 739 pages. The chapters are relatively short and generally quick reads comparable to a journal article. In the foreword, the editors state that this book is intended as an interdisciplinary reference seeking to reach a broad audience and suitable to all audiences. In both respects, this book is highly effective and represents a significant contribution to a variety of fields. It pushes the boundaries of what forensic casework used to be and the role of forensic scientists both within and outside of their discipline. The volumes also showcase a shift in the forensic humanitarian field to supporting local actors in times of humanitarian crisis. Through the themes of forensic science as humanitarian action and comparing this forensic work to "normal deathwork" (Chapter 3), these collected works are able to demonstrate a wide range of perspectives on the recovery and identification process for human remains. A key strength of this work is the diversity of perspectives brought to bear on these issues. Both the editors and contributors have diverse backgrounds representing regions across the globe, various disciplines within the forensic sciences and humanitarian fields, as well as

Friend, Amanda (2021) Review of Forensic Science and Humanitarian Action: Interacting with the Dead and the Living, by Roberto C. Parra, Sara C. Zapico, and Douglas H. Ubelaker. New Florida Journal of Anthropology, 1(2), 2-4 DOI:10.32473/nfja.v1i2.126474 
holding positions in academia, non-governmental organizations, governmental agencies, and forensic laboratories. The case studies and theoretical framework illustrated within these chapters also reinforce the interdisciplinary nature of forensic science as humanitarian action, providing jumping-off points for discussions regarding implementing successful approaches to new problems and the outcomes of the work.

The writing is easily accessible for diverse audiences, making it an ideal text for upper level undergraduate and graduate students. There are high-level discussions of theory and implications of humanitarian action in the first section and more technical and methodological discussions in the third and fourth sections focusing on isotopes and DNA respectively. These sections' overall conclusions and contributions can still be understood in broad terms by those unfamiliar with these fields, but those with more expertise can better critically evaluate the work and engage in the discussion of challenges and potential solutions posed in these chapters.

For educators, this volume could be used in a myriad of courses (e.g., legal anthropology, forensic anthropology, human rights, forensic sciences, and sociology), it provides a broad overview of the implementation and results of forensic science while also challenging these processes. It can provide students with a number of potential roles that individuals can play in humanitarian work and future careers relating to the dead. These chapters are not in-depth, exhaustive reviews of the various fields of forensic sciences, but they do provide background into various fields and include jumping-off points for further discussion and inquiry. There are four chapters $(37,39,43$, and 44$)$ that show images of human skeletal remains making this book easily adapted for audiences where images of human remains would not be appropriate. These chapters could be excluded from discussion or the limited number of images could be redacted. Additionally, the text places the dead into the context of the social structures of the living and reminds the field that the forensic sciences are not occurring in a vacuum by expanding on the experiences of those left behind and engaging with the identification processes.

Successes versus challenges are also a running theme throughout the volume. As Oran Finnegan's foreword notes, new techniques and methods successfully developed and implemented in the field raise expectations to what forensic science can do. However, circumstances that pose difficulty in the course of normal deathwork are often exacerbated in humanitarian circumstances, further limiting the chances of successful recovery and identification. Chapters that were particularly successful at presenting this dichotomy and that illustrate a wide range of issues include Chapters 10, 34, and 45 . Throughout both volumes, the work engages with this dichotomy through a thoughtful discussion of the legal framework, concept of identity, case studies, and the roles the community plays in forensic science. By taking this approach, this book demonstrates how holistic forensic science as humanitarian action is and challenges its practitioners to become more holistic with their engagement with other fields, collaborations, and the communities they serve. These concepts are particularly critical for forensic practitioners working in humanitarian work, as well as thinking more holistically about work they engage in within their own communities. Forensic casework is often posited as objective science, and forensic anthropologists and other forensic scientists are often removed from the ramifications of their work. These volumes challenge practitioners to reexamine how this humanitarian

Friend, Amanda (2021) Review of Forensic Science and Humanitarian Action: Interacting with the Dead and the Living, by Roberto C. Parra, Sara C. Zapico, and Douglas H. Ubelaker. New Florida Journal of Anthropology, 1(2), 2-4 DOI:10.32473/nfja.v1i2.126474 
work can impact a community and to be more thoughtful in our approaches in considering the communities we serve, which is particularly cogent today.

Friend, Amanda (2021) Review of Forensic Science and Humanitarian Action: Interacting with the Dead and the Living, by Roberto C. Parra, Sara C. Zapico, and Douglas H. Ubelaker. New Florida Journal of Anthropology, 1(2), 2-4 DOI:10.32473/nfja.v1i2.126474 